УДК 517.1

\title{
Nanofluid Flow over a Stretching Surface in Presence of Chemical Reaction and Thermal Radiation: An Application of Lie Group Transformation
}

\author{
Kalidas Das* \\ Amit Sarkar ${ }^{\dagger}$ \\ Prabir Kumar Kundu ${ }^{\ddagger}$ \\ Dept. of Mathematics \\ A.B.N. Seal College \\ Cooch Behar, W.B., Pin-736101
}

India

Received 10.08.2016, received in revised form 26.11.2016, accepted 06.02.2017

This paper concerns with a steady MHD boundary layer flow of an electrically conducting nanofluid over a vertical permeable stretching surface with variable stream conditions. The transport model includes the effect of Brownian motion with thermophoresis in presence of chemical reaction and thermal radiation. The group theoretic method is used to find the symmetries of the governing partial differential equations. The reduced equations are solved numerically by employing a fourth order Runge-Kutta method and Shooting techniques to predict the heat and mass transfer characteristics of the nanofluid flow. Numerical results are presented through graphs and tables for several sets of values of the involved parameters of the problem and discussed in details from the physical point of view.

Keywords: nanofluid, Lie group transformation, magnetic field, chemical reaction, Brownian motion, thermal radiation.

DOI: 10.17516/1997-1397-2017-10-2-146-157.

\section{Introduction and preliminaries}

In the last few years, heat transfer characteristics of nanofluids is a topic of major contemporary interest both in applied sciences and engineering. The term nanofluid refers to a liquid containing a suspension of submicronic solid particles (nanoparticles), diameter less than $50 \mathrm{~nm}$, was first introduced by Choi [1]. Fluids such as water, toluene, ethylene glycol and oil are poor heat transfer fluids. The choice of base fluid-particle combination depends on the application for which the nanofluid is intended. Recent research on nanofluid showed that nanoparticles changed the fluid characteristics because thermal conductivity of these particles was higher than regular fluids. The common nanoparticles that have been used are copper, aluminum, iron and titanium or their oxides. Experimental studies [2-4] show that even with the small volumetric fraction of nanoparticles (usually less than 5\%), the thermal conductivity of the base liquid can be enhanced by $5-20 \%$. The enhanced thermal conductivity of nanofluid together with the thermal conductivity of the regular liquid and turbulence induced by their motion contributes to a remarkable improvement in the convective heat transfer coefficient. Various benefits of the application of nanofluids include: improved heat transfer, heat transfer system size reduction, micro-channel cooling and miniaturization of the system. There have been published several

\footnotetext{
*kd kgec@rediffmail.com

$\dagger$ amitformath@gmail.com

${ }^{\ddagger}$ kunduprabir@yahoo.co.in

(c) Siberian Federal University. All rights reserved
} 
recent papers [5-7] on the mathematical and numerical modelling of convective heat transfer in nanofluids. The boundary layer flow of a nanofluid caused by a stretching surface has drawn the attention of many researchers [8-10]. Kandasamya et al. [11] investigated MHD boundary layer flow of a nanofluid over a stretching surface using scaling group transformation. Recently, Hamad and Ferdows [12] obtained the similarity solution of stagnation-point flow towards a heated porous stretching sheet saturated with a nanofluid.

The effect of radiation on MHD flow and heat transfer problem have become more important industrially. The radiation effect is quite significant at high operating temperature. In engineering areas, many processes occur at high temperature and so the knowledge of radiation heat transfer becomes important for making of reliable equipment, gas turbines, nuclear plants and various space vehicles. Cogley et al. [13] showed that the fluid does not absorb its own emitted radiation in the optically thin limit but the fluid does absorb radiation emitted by the boundaries. The radiation effects on heat and mass transfer boundary layer flow have been studied by many authors [14-16]. Recently Abdul-Kahar et al. [17] analyzed the boundary-layer flow of a nanofluid past a porous vertical stretching surface in the presence of chemical reaction with heat radiation using scaling group transformation.

The recent trend in the field of chemical reaction analysis is to give a mathematical model for the system to predict the reactor performance. The study of heat and mass transfer with chemical reaction is of considerable importance for food processing, design of chemical processing equipment, distribution of temperature and moisture over agricultural fields, formation and dispersion of fog. In addition, in many chemical engineering processes, chemical reaction takes place between a foreign mass and the working fluid which moves due to the stretching of a surface. The first order chemical reaction which is directly proportional to the species concentration, is the simplest form of different order chemical reaction. Patil and Kulkarni [18] considered the effects of chemical reaction on free convection flow of a polar fluid through a porous medium in the presence of internal heat generation. The problems involving chemical reactions in a nanofluid flow can be found in the studies of Kandasamy et al. [19], Yazdi et al. [20] and Kandasamy et al. [21].

The objective of the paper is to study the effects of thermal radiation and chemical reaction on MHD boundary layer flow of an electrically conducting nanofluid over a vertical stretching surface using scaling group of transformations. The results of the present problem have extensive applications in the field of engineering and medical sciences.

\section{Convective transport model}

Consider a steady free convection boundary layer flow, heat and mass transfer of an electrically conducting nanofluid over a vertical permeable stretching sheet emerging out of a slit at origin and moving with the non-uniform velocity $U(x)$ in the presence of thermal radiation and first order chemical reaction. The flow is assumed to be in the $x$-direction which is taken along the plate and $y$-axis is normal to it as shown in Fig. 1.

The effect of Brownian motion and thermophoresis are taken into account in the flow. A uniform transverse magnetic field of strength $B(x)=\frac{B_{0}}{\sqrt{x}}$ is applied parallel to the $y$-axis. The magnetic Reynolds number of the flow is taken to be small enough so that induced magnetic field is assumed to be negligible in comparison with applied magnetic field. Applying the OberbeckBoussinesq approximations to simplify the Boungiorno [4] convective transport equations, we obtain the following governing equations:

$$
\frac{\partial u}{\partial x}+\frac{\partial v}{\partial y}=0
$$




$$
\begin{gathered}
u \frac{\partial u}{\partial x}+v \frac{\partial u}{\partial y}=\nu \frac{\partial^{2} u}{\partial y^{2}}-\frac{\sigma B^{2}(x)}{\rho_{f}} u+\left[\left(1-C_{\infty}\right) \rho_{f_{\infty}} \beta\left(T-T_{\infty}\right)-\left(\rho_{p}-\rho_{f_{\infty}}\right)\left(C-C_{\infty}\right)\right] g \\
u \frac{\partial T}{\partial x}+v \frac{\partial T}{\partial y}=\frac{\kappa}{(\rho c)_{f}} \frac{\partial^{2} T}{\partial y^{2}}+\tau\left[D_{B} \frac{\partial C}{\partial y} \frac{\partial T}{\partial y}+\frac{D_{T}}{T_{\infty}}\left(\frac{\partial T}{\partial y}\right)^{2}\right]-\frac{1}{(\rho c)_{f}} \frac{\partial q_{r}}{\partial y} \\
u \frac{\partial C}{\partial x}+v \frac{\partial C}{\partial y}=D_{B} \frac{\partial^{2} C}{\partial y^{2}}+\frac{D_{T}}{T_{\infty}} \frac{\partial^{2} T}{\partial y^{2}}-k\left(C-C_{\infty}\right),
\end{gathered}
$$

where $u, v$ are the velocity components along the $x$ and $y$-axis respectively, $\nu$ is the kinematic viscosity of the base fluid, $\sigma$ is the electrical conductivity, $\rho_{f}$ is the density of base fluid, $\rho_{p}$ is the nanoparticle density, $T$ is the temperature, $\tau=(\rho c)_{p} /(\rho c)_{f}$ is the ratio of the effective heat capacity of the nanoparticle material and the base fluid , $\beta$ is the volumetric thermal expansion coefficient of the base fluid, $g$ is the acceleration due to gravity, $q_{r}$ is the radiative heat flux, $C$ is the nanoparticle volume fraction, $D_{B}$ is the Brownian diffusion coefficient, $D_{T}$ is the thermophoretic diffusion coefficient, $\kappa$ is the effective thermal conductivity of nanofluid, $k$ is the rate of chemical reaction and the subscript $\infty$ denotes the values at large values of $y$ where the fluid is quiescent.

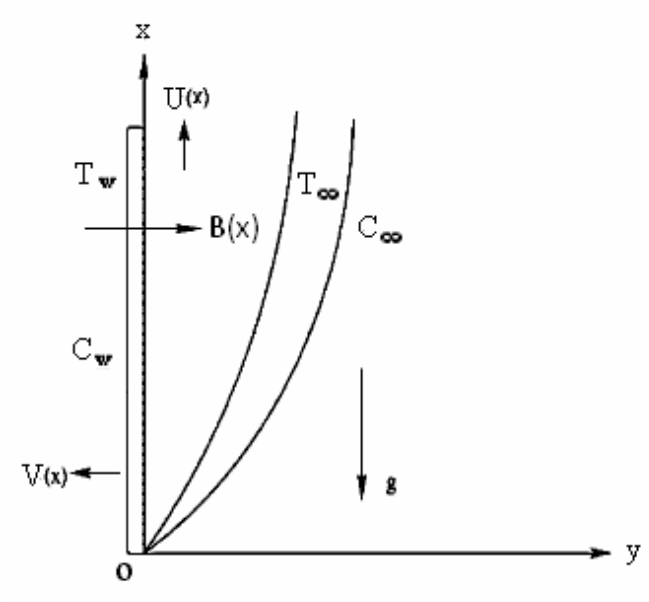

Fig. 1. Physical model and coordinate system

The associated boundary conditions are

$$
\left.\begin{array}{l}
u=U(x), v=V(x), T=T_{w}, C=C_{w} \text { at } y=0, \\
u \rightarrow 0, T \rightarrow T_{\infty}, C \rightarrow C_{\infty} \text { as } y \rightarrow \infty
\end{array}\right\}
$$

where $V(x)$ is the velocity of suction/injection, $T_{w}$ is the wall temperature and $C_{w}$ is the nanoparticle volume fraction at the wall.

The radiative heat flux term $q_{r}$ along y direction, is described by the Rosseland approximation such that

$$
q_{r}=-\frac{4 \sigma_{1}}{3 k_{1}} \frac{\partial T^{4}}{\partial y}
$$

where $\sigma_{1}$ is the Stefan-Boltzmann constant and $k_{1}$ is the mean absorption coefficient. Let us assume that the temperature difference within the boundary layer such that $T^{4}$ can be expressed 
as a linear function of temperature. Thus $T^{4}$ can be expressed as a Taylor's series expansion about the free stream temperature $T_{\infty}$ and neglecting higher order terms, one may get

$$
T^{4}=4 T_{\infty}^{3} T-3 T_{\infty}^{4}
$$

Using Eq.(6) in Eq.(3) we obtain

$$
u \frac{\partial T}{\partial x}+v \frac{\partial T}{\partial y}=\frac{\kappa}{(\rho c)_{f}} \frac{\partial^{2} T}{\partial y^{2}}+\tau\left[D_{B} \frac{\partial C}{\partial y} \frac{\partial T}{\partial y}+\frac{D_{T}}{T_{\infty}}\left(\frac{\partial T}{\partial y}\right)^{2}\right]-\frac{16 T_{\infty}^{3} \sigma_{1}}{3(\rho c)_{f} k_{1}} \frac{\partial^{2} T}{\partial y^{2}}
$$

The streamwise velocity and the suction/injection velocity are taken as (Kandasamy et al. [11])

$$
U(x)=c x^{m}, \quad V(x)=V_{0} x^{(m-1) / 2},
$$

where $c>0$ is constant and the power-law exponent $\mathrm{m}$ is also constant. In the present paper, we take $c=1$ and $m=\frac{1}{2}$.

The introduction of the following non-dimensional variables

$$
\theta=\frac{T-T_{\infty}}{T_{w}-T_{\infty}}, \quad \phi=\frac{C-C_{\infty}}{C_{w}-C_{\infty}}
$$

and the introduction of the stream function $\psi$, defined by $u=\frac{\partial \psi}{\partial y}$ and $v=-\frac{\partial \psi}{\partial x}$, leads to Eqs. $(1),(2),(4)$ and (8) taking the following non-dimensional form

$$
\begin{gathered}
\frac{\partial \psi}{\partial y} \frac{\partial^{2} \psi}{\partial x \partial y}-\frac{\partial \psi}{\partial x} \frac{\partial^{2} \psi}{\partial y^{2}}-\nu \frac{\partial^{3} \psi}{\partial y^{3}}=-\frac{\sigma B_{0}^{2}}{\rho_{f}} \frac{\partial \psi}{\partial y}+\left(1-\phi_{\infty}\right) \rho_{f_{\infty}} \beta g \theta \Delta \theta-\left(\rho_{p}-\rho_{f_{\infty}}\right) g \phi \Delta \phi \\
\frac{\partial \psi}{\partial y} \frac{\partial \theta}{\partial x}-\frac{\partial \psi}{\partial x} \frac{\partial \theta}{\partial y}= \\
{\left[\frac{\kappa}{(\rho c)_{f}}+\frac{16 T_{\infty}^{3} \sigma_{1}}{3(\rho c)_{f} k_{1}}\right] \frac{\partial^{2} \theta}{\partial y^{2}}+\tau\left[D_{B} \Delta \phi \frac{\partial \phi}{\partial y} \frac{\partial \theta}{\partial y}+\frac{D_{T}}{T_{\infty}} \Delta \theta\left(\frac{\partial \theta}{\partial y}\right)^{2}\right]} \\
\frac{\partial \psi}{\partial y} \frac{\partial \phi}{\partial x}-\frac{\partial \psi}{\partial x} \frac{\partial \phi}{\partial y}=D_{B} \frac{\partial^{2} \phi}{\partial y^{2}}+\frac{D_{T} \Delta \theta}{T_{\infty} \Delta \phi} \frac{\partial^{2} \theta}{\partial y^{2}}-k \phi
\end{gathered}
$$

with the boundary conditions

$$
\left.\begin{array}{l}
\frac{\partial \psi}{\partial y}=x^{m}, \frac{\partial \psi}{\partial x}=-V_{0} x^{\frac{m-1}{2}}, \theta=1, \phi=1 \text { at } y=0, \\
\frac{\partial \psi}{\partial y} \rightarrow 0, \theta \rightarrow 0, \phi \rightarrow 0 \text { as } y \rightarrow \infty
\end{array}\right\}
$$

where $\Delta \theta=T_{w}-T_{\infty}$ and $\Delta \phi=C_{w}-C_{\infty}$.

To find the similarity solutions of Eqs. (11)-(14), it is equivalent to determine the invariant solutions of these equations under a particular continuous one parameter group (Kandasamy et al. [19]). The scaling group of transformations is one of the methods from a transformation group and defined by the following group $(\Gamma)$

$$
\left.\Gamma: x^{*}=x e^{\varepsilon \alpha_{1}}, y^{*}=y e^{\varepsilon \alpha_{2}}, \psi^{*}=\psi e^{\varepsilon \alpha_{3}}, \theta^{*}=\theta e^{\varepsilon \alpha_{6}}, \phi^{*}=\phi e^{\varepsilon \alpha_{7}}\right\} .
$$

Here $\varepsilon(\neq 0)$ is the parameter of the group and $\alpha$ 's are arbitrary real numbers. The transformations in (15) may be treated as a point-transformation which transforms coordinates $(x, y, \psi, \theta, \phi)$ to the coordinates $\left(x^{*}, y^{*}, \psi^{*}, \theta^{*}, \phi^{*}\right)$. After tedious calculations we obtain the following similarity transformations:

$$
y^{*} x^{*^{-1 / 4}}=\eta, \psi^{*}=x^{*^{3 / 4}} f(\eta), \theta^{*}=\theta(\eta), \phi^{*}=\phi(\eta) .
$$


Using the transformations in (15), we get from (11)-(13) the following similarity equations:

$$
\begin{gathered}
f^{\prime \prime \prime}+\frac{1}{\operatorname{Pr}}\left(\frac{3}{4} f f^{\prime \prime}-\frac{1}{2} f^{\prime 2}\right)+R a(\theta-N r \phi)-M f^{\prime}=0, \\
\left(1+\frac{4}{3} N\right) \theta^{\prime \prime}+\frac{3}{4} \operatorname{Pr} f \theta^{\prime}+N b \theta^{\prime} \phi^{\prime}+N t \theta^{\prime 2}=0, \\
\phi^{\prime \prime}+\frac{3}{4} L e f \phi^{\prime}+\frac{N t}{N b} \theta^{\prime \prime}-\gamma \phi=0 .
\end{gathered}
$$

The boundary conditions (14) now become

$$
\left.\begin{array}{l}
f=S, f^{\prime}=1, \theta=1, \phi=1 \quad \text { at } \eta=0 \\
f^{\prime} \rightarrow 0, \theta \rightarrow 0, \phi \rightarrow 0 \text { as } \eta \rightarrow \infty
\end{array}\right\}
$$

Here prime denotes differentiation with respect to similarity independent variable $\eta, \operatorname{Pr}=\frac{\nu}{\alpha}$ is the Prandtl number, $R a=\frac{\left(1-\phi_{\infty}\right) \beta g \Delta \theta}{\nu}$ is the local Rayleigh number, $L e=\frac{\alpha}{D_{B}}$ is the Lewis number, $N r=\frac{\left(\rho_{p}-\rho_{f_{\infty}}\right) \Delta \phi}{\rho_{f_{\infty}} \beta \Delta \theta\left(1-\phi_{\infty}\right)}$ is the buoyancy ratio, $N b=\frac{D_{B} \Delta \phi(\rho c)_{p}}{\kappa}$ is the Brownian motion parameter, $N t=\frac{D_{T} \Delta \theta(\rho c)_{p}}{\kappa T_{\infty}}$ is the thermophoresis parameter, $M=\frac{\sigma B_{0}^{2}}{\rho_{f}}$ is the magnetic parameter, $N=\frac{4 T_{\infty}^{3} \sigma_{1}}{k_{1} \kappa}$ is the thermal radiation parameter, $\gamma=\frac{U k}{D_{B}}$ is the chemical reaction parameter and $S=-\frac{4}{3} V_{0}$ is the suction/injection parameter.

The parameters in which we are interested for our problem are the reduced Nusselt number Nur and the reduced Sherwood number Shr. These quantities can be defined as:

$$
\begin{aligned}
& N u r=R e_{x}^{-1 / 2} N u=-\theta^{\prime}(0), \\
& S h r=R e_{x}^{-1 / 2} S h=-\phi^{\prime}(0) .
\end{aligned}
$$

\section{Numerical method}

The set of highly non-linear differential equations (17)-(19) together with the boundary conditions (20) are solved numerically by using a fourth order Runge-Kutta method and Shooting techniques with a systematic guessing of $f^{\prime}(0), \theta^{\prime}(0)$ and $\phi^{\prime}(0)$. The computations were done by a program which uses a symbolic and computational computer language MATHEMATICA. The step size $\Delta \eta=0.001$ is selected to be satisfactory for a convergence criterion of $10^{-6}$ in all cases. We have tried to solve a sequence of problems posed on increasingly larger intervals to verify the solution's consistent behavior as the boundary approaches to $\infty$. We take infinity condition at a large but finite value of $\eta$ where no considerable variation in flow characteristics occur.

In the absence of thermal radiation and chemical reaction, the present investigation coincides with that of Kandasamy et al. [11]. To check the validity of the present code, the values of $-\theta^{\prime}(0)$ have been calculated for $N=\gamma=0$ and for different values of Prandtl numbers $\operatorname{Pr}$ in Tab. 1. One may observed from the table that the data produced by the present code and those of Khan and Pop [9] and Kandasamya et al. [11] show excellent agreement and, so the use of the present numerical code for current model is justified. 
Table 1. Comparison of the results for $-\theta^{\prime}(0)$ with previous published works

\begin{tabular}{lccc}
\hline$P r$ & Khan and Pop [9] & Kandasamy et al.[11] & Present work \\
\hline 0.07 & 0.0663 & 0.066129 & 0.066131 \\
0.20 & 0.1691 & 0.169136 & 0.169136 \\
0.70 & 0.4539 & 0.454285 & 0.454286 \\
2.00 & 0.9113 & 0.911423 & 0.911430 \\
\hline
\end{tabular}

\section{Numerical results and discussions}

A comprehensive numerical parametric study are conducted and the results are reported in terms of graphs and tables. In the simulation the default values of the parameters are considered as $\operatorname{Pr}=1.0, L e=3.0, R a=1.0, N r=0.5, M=0.5, S=0.6, N t=1.0, N b=0.3, \gamma=0.5$ and $N=0.5$ unless otherwise specified. Tab. 2 presents the effect of various parameter on the reduced Nusselt number and the reduced Sherwood number. The results show that the heat transfer rate at the plate decreases with increasing values of $M, N, N b$ and $N t$. It is noteworthy that the thermophoretic effect exerts a strong influence on the heat transfer; reducing it by almost $12 \%$ as thermophoresis parameter changes from 0.0 to 0.5 . This reduction is due to the nanoparticles of high thermal conductivity being driven away from the hot sheet to the quiescent fluid. But the impact of chemical reaction parameter on the heat transfer rate is not significant. It is also found from tables that an increase in $N b$ and $\gamma$ lead to increase in the values of the rate of mass transfer while the effect is reverse for $N t$.

Table 2. Effects of $M, N, N b, N t$ and $\gamma$ on $N u r$ and $S h r$

\begin{tabular}{ccccccc}
\hline$M$ & $N$ & $N b$ & $N t$ & $\gamma$ & Nur & Shr \\
\hline 0.0 & 0.5 & 0.3 & 1.0 & 0.5 & 0.705766 & 2.58526 \\
0.5 & & & & & 0.686676 & \\
1.5 & & & & & 0.662363 & \\
0.5 & 0.0 & & & & 0.739918 & 2.53671 \\
& 0.6 & & & & 0.675210 & \\
& 1.5 & & & & 0.583676 & \\
& 0.5 & 0.1 & & & 0.991298 & -4.45810 \\
& 0.2 & & & 0.985531 & -0.487148 \\
& 0.4 & & & 0.910270 & 1.45572 \\
& 0.3 & 0.0 & & 0.881860 & 2.95436 \\
& & 0.5 & & 0.776522 & 2.72817 \\
& & 1.5 & & 0.609971 & 2.48407 \\
& & 1.0 & 0.0 & 0.695743 & 2.36009 \\
& & & 0.3 & & 2.49393 \\
& & & 0.6 & & 2.61792 \\
\hline
\end{tabular}

In Figs. 2-4, we presented the behavior of the fluid velocity for various material parameters. The effect of the magnetic field parameter $M$ on the fluid velocity is shown in Fig. 2. It is observed that the fluid velocity decreases with increasing values of $M$ and so decrease the thickness of momentum boundary layer. The reason behind this phenomenon is that application of magnetic field to an electrically conducting nanofluid give rise to a resistive type force called the Lorentz 
force which slow down the motion of the fluid in the boundary layer. The velocity decreases as $\eta$ increases for a fixed value of the thermal radiation parameter $N$ as shown in Fig. 3 but the velocity distribution across the boundary layer increases with the increasing values of $N$ for a non-zero fixed value of $\eta$. The physics behind this reason is that the increased radiation increases the thickness of momentum boundary layer, which ultimately enhances the velocity. Fig. 4 depicts the effect of the Brownian motion parameter $N b$ on the fluid velocity. It is observed that the increase in the values of $N b$ results in the increase of the velocity distribution in the boundary layer region. In figure all profiles decay to the free stream value of zero as $\eta \rightarrow \infty$.

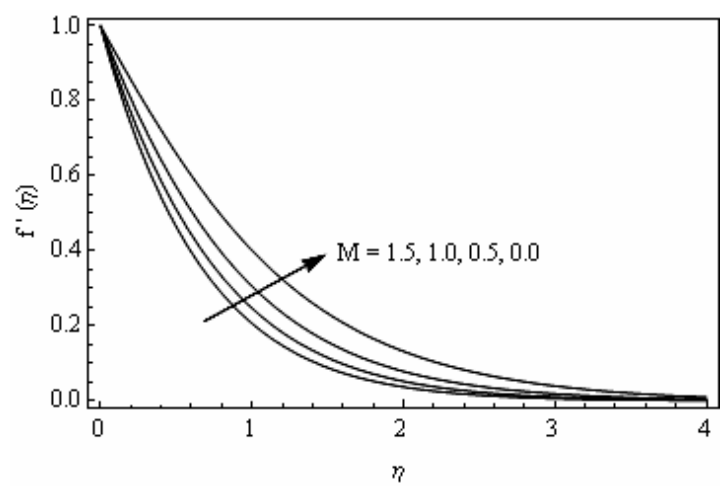

Fig. 2. Velocity profiles for various values of $M$

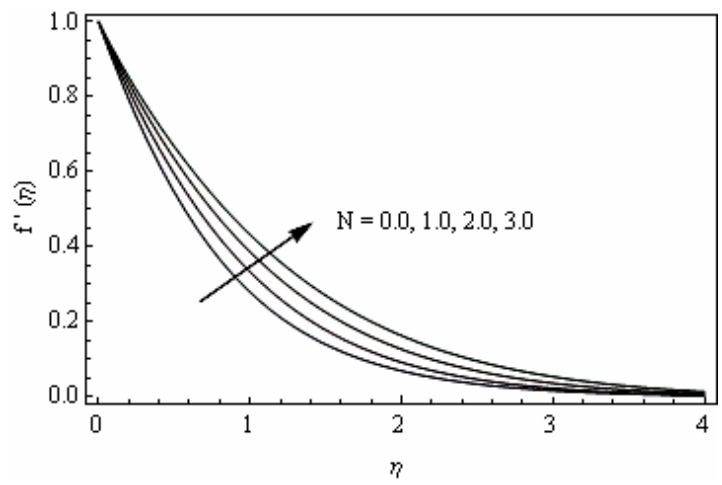

Fig. 3. Velocity profiles for various values of $N$

Figs. 5-8 illustrate the variation of the nanofluid temperature $\theta$ versus $\eta$ for various values of the physical parameters. Fig. 5 shows that the fluid temperature is the maximum near the boundary layer region and it decreases on increasing boundary layer coordinate $\eta$ to approach free stream value. Also nanofluid temperature increases on increasing the magnetic field parameter $M$ in the boundary layer region and so the thickness of the thermal boundary layer increases. Fig. 6 demonstrate the effects of thermal radiation parameter $N$ on fluid temperature in the presence of Brownian motion and thermophoresis. It is observed from the figure that temperature $\theta(\eta)$ decreases on increasing $N$ in the boundary layer region and is maximum at the surface of the plate. The increase in radiation parameter means the release of heat energy from the flow region and so the fluid temperature decreases as the thermal boundary layer thickness becomes thinner. Fig. 7 illustrates the typical temperature profiles for various values of the Brownian motion $N b$. It may be noted that as $N b$ increases, the fluid temperature increases only in a region close 


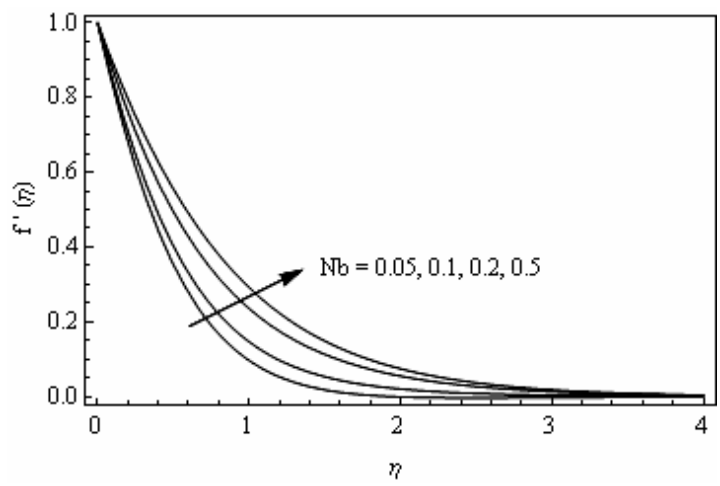

Fig. 4. Velocity profiles for various values of $\mathrm{Nb}$

to the sheet as the curves tend to merge at larger distances from the sheet. Fig. 8 shows the influence of the thermophoresis parameter $N t$ on the dimensionless temperature function $\theta(\eta)$. For a non-zero fixed value of $\eta$, temperature distribution across the boundary layer increases with the increasing values of $N t$ and hence the thickness of thermal boundary layer increases.

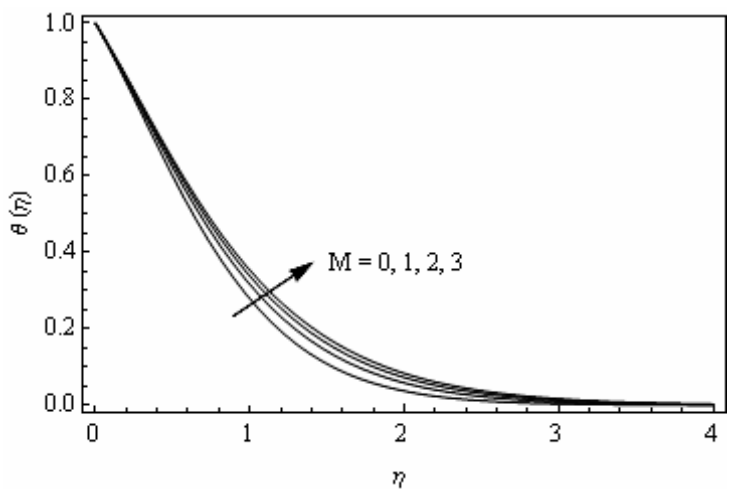

Fig. 5. Temperature profiles for various values of $M$

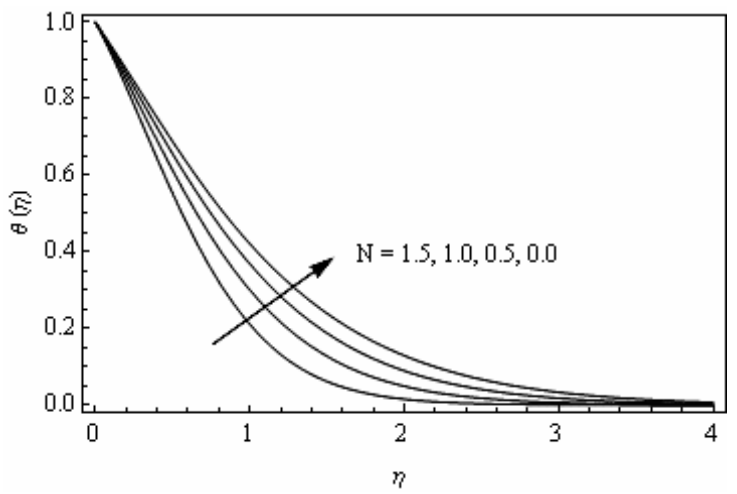

Fig. 6. Temperature profiles for various values of $N$ 


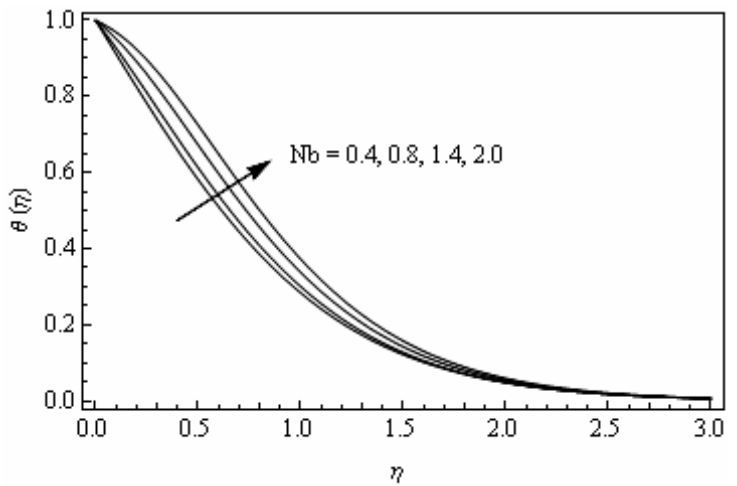

Fig. 7. Temperature profiles for various values of $N b$

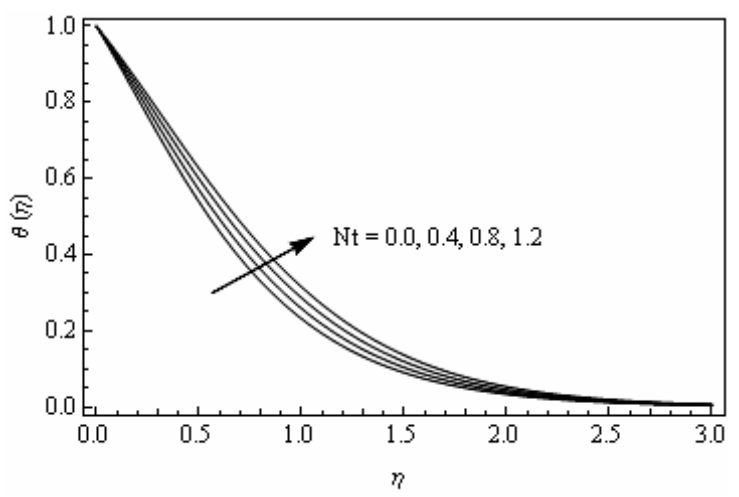

Fig. 8. Temperature profiles for various values of $N t$

Figs. 9-11 depict nanoparticle concentration profiles against $\eta$ for varying values of thermophysical parameters in the boundary layer. The impact of the chemical reaction parameter $\gamma$ on nanoparticle concentration distribution is presented in Fig. 9. It is seen that the effect of increas-

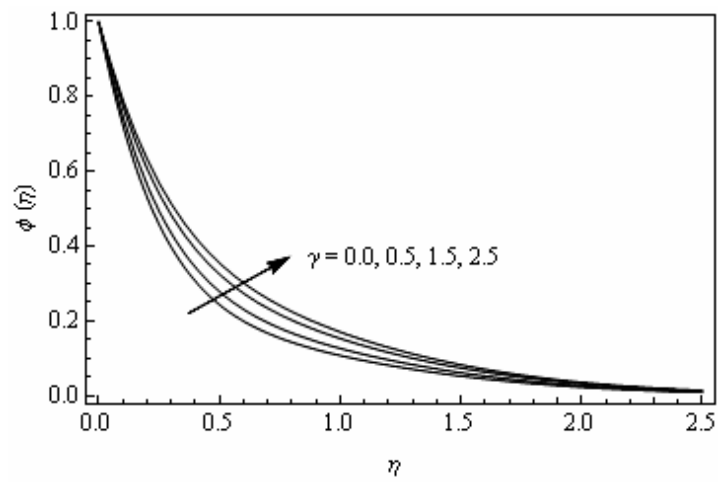

Fig. 9. Nanoparticle concentration profiles for various values of $\gamma$

ing values of the chemical reaction parameter results in decreasing nanoparticle concentration distribution across the boundary layer. The reason for this trend is that the concentration boundary layer becomes thin for larger chemical reaction parameter $\gamma$. Fig. 10 presents typical profiles 
for nanoparticle concentration for different values of the Brownian motion parameter Nb. Fig. 11 illustrates the influence of the thermophoretic parameter $N t$ on the nanoparticle concentration profiles. It is seen that nanoparticle concentration of the fluid increases with the increase of the thermophoretic parameter $N t$. As seen in figure, the effect of $N b$ on nanoparticle concentration is noticeable only in a region close to the sheet as the curves tend to merge at larger distances from the sheet.

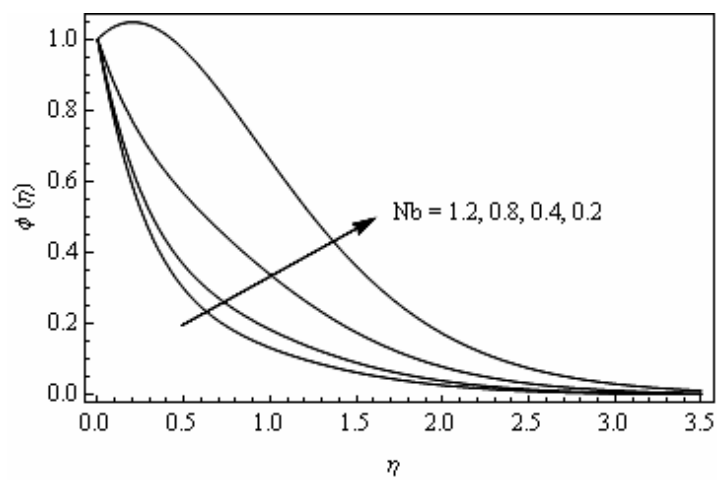

Fig. 10. Nanoparticle concentration profiles for various values of $\mathrm{Nb}$

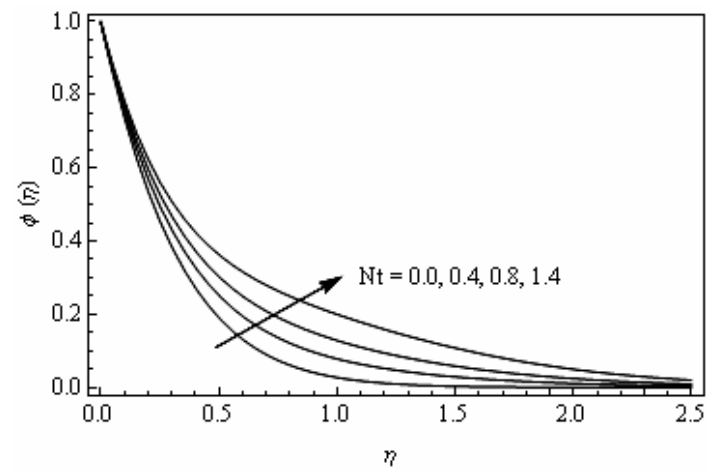

Fig. 11. Nanoparticle concentration profiles for various values of $\mathrm{Nt}$

\section{Conclusions}

Under the assumption of Brownian motion and thermophoresis, the present study gives results, for MHD boundary layer flow of an electrically conducting nanofluid over a vertical stretching surface in the presence of thermal radiation and chemical reaction. The reduced equations are solved numerically to predict the heat and mass transfer characteristics of the nanofluid flow. The following conclusion can be drawn:

- The effect of increasing thermal radiation parameter with chemical reaction on a nanofluid is to increase the flow velocity which in turn, causes the temperature to decrease.

- The strength of magnetic field diminishes the fluid velocity whereas the temperature enhances within the boundary layer region.

- The volume fraction of nanoparticles is a key parameters for studying the effect of nanoparticles on the flow fields and temperature distribution. 
- Both the velocity and temperature increase due to Brownian motion in the boundary layer region.

- The chemical reaction parameter decreases nanoparticle concentration distribution across the boundary layer.

- The reduced Nusselt number is a decreasing function of each of $M, N, N b$ and $N t$.

- The reduced Sherwood number increases with increase in the values of $N b$ and $\gamma$ but effect is opposite for $N t$.

The first author wishes to express his cordial thanks to UGC, Govt. of INDIA for providing financial support through the Minor Research Project (PSW-106/14-15)to undertake this research work. Also the authors wish to express their cordial thanks to reviewers for valuable comments to improve the presentation of this article.

\section{References}

[1] S.U.S Choi, Enhancing thermal conductivity of fluids with nanoparticles, Developments and Applications of Non-Newtinian flows, 66(1995), 99-105.

[2] J.A.Eastman, S.L.S.S.Choi, W.Yu, L.J.Thompson, Anomalously increased effective thermal conductivity of ethylene glycol-based nanofluids containing copper nanoparticles, Appl. Phys. Lett., 78(2001), no. 6, 718-720.

[3] S.Das, Temperature dependence of thermal conductivity enhancement for nanofluids, $J$. Heat Transfer, 125(2003), 567-574.

[4] J.Buongiorno, Convective transport in nanofluids, ASME J. Heat Transfer., 128(2006), 240-250.

[5] A.V.Kuznetsov, D.A.Nield, Natural convective boundary layer flow of a nanofluid past a vertical plate, Int. J. Thermal Sci., 49(2010), 243-247.

[6] M.M.Rashidi, E.Erfani, (2011) The modified differential transform method for investigating nano boundary-layers over stretching surfaces, Int. J. of Numerical Methods for Heat and Fluid Flow, 21(2011), no. 7, 864-883.

[7] A.Aziz, W.A.Khan, Natural convective boundary layer flow of a nanofluid past a convectively heated vertical plate, Int. J. Thermal Sci., 52(2012), 83-90.

[8] R.A.Van Gorder, E.Sweet, K.Vajravelu, Nano boundary layers over stretching surfaces, Commun. Nonlinear Sci. Numer. Simulat., 15(2010), 1494-1500.

[9] W.A.Khan, I.Pop, Boundary-layer flow of a nanofluid past a stretching sheet, Int. J. Heat Mass Trans., 53(2010), 2477-2483.

[10] O.D.Makinde, A.Aziz, Boundary layer flow of a nanofluid past a stretching sheet with a convective boundary condition, Int. J. Thermal Sci.,50(2011), 1326-1332.

[11] R.Kandasamya, P.Loganathanb, P.Puvi Arasub, Scaling group transformation for MHD boundary-layer flow of a nanofluid past a vertical stretching surface in the presence of suction/injection, Nuc. Eng. Design., 241(2011), 2053-2059.

[12] M.A.A.Hamad, M.Ferdows, Similarity solution of boundary layer stagnation-point flow towards a heated porous stretching sheet saturated with a nanofluid with heat absorption/generation and suction/blowing: a Lie group analysis, Commun. Nonlinear Sci. Numer. Simulat., 17(2012), 132-140. 
[13] A.C.Cogley, W.E.Vincenty, S.E.Gilles, Differential approximation for radiation in a non-gray gas near equilibrium, AIAA J., 6(1968), 551-553.

[14] O.D.Makinde, Free convection flow with thermal radiation and mass transfer past a moving vertical porous plate, Int. Comm. Heat. Mass Transfer, 32(2005), 1411-1419.

[15] F.S.Ibrahim, A.M.Elaiw, A.A.Bakr, Influence of viscous dissipation and radiation on unsteady MHD mixed convection flow of micropolar fluids, Appl. Math. Inf. Sci., 2(2008), $143-162$.

[16] K.Das, Impact of thermal radiation on MHD slip flow over a flate plate with variable fluid properties, Heat. Mass. and Transfer, 48(2011), 767-778.

[17] R.Abdul-Kahar, R.Kandasamy, I.Muhaimin, Scaling group transformation for boundarylayer flow of a nanofluid past a porous vertical stretching surface in the presence of chemical reaction with heat radiation, Computers and Fluids, 52(2011), 15-21.

[18] P.M.Patil, P.S.Kulkarni, Effects of chemical reaction on free convective flow of a polar fluid through a porous medium in the presence of internal heat generation, Int. J. Therm. Sci., 47(2008), 1043-1054.

[19] R.Kandasamy, I.Muhaimin, H.B.Saim, Lie group analysis for the effect of temperaturedependent fluid viscosity with thermophoresis and chemical reaction on MHD free convective heat and mass transfer over a porous stretching surface in the presence of heat source/sink, Commun. Nonlinear Sci. Numer. Simulat., 15(2010), no. 8, 2109-2123.

[20] M.H.Yazdi, S.Abdullah, I.Hashim, K.Sopian, Slip MHD liquid flow and heat transfer over non-linear permeable stretching surface with chemical reaction, Int. J. Heat. Mass. Trans., 54(2011), 3214-3225.

[21] R.Kandasamya, T.Hayatb, S.Obaidatc, Group theory transformation for Soret and Dufour effects on free convective heat and mass transfer with thermophoresis and chemical reaction over a porous stretching surface in the presence of heat source/sink, Nuclear Engineering and Design, 241(2011), no. 6, 2155-2161

\section{Нанодисперсия обтекания над поверхностью растяжения с участием химической реакции и теплового излучения: применение преобразования группы Ли}

\section{Калидас Дас, Амит Саркар, Пробир Кумар Кунду}

Департамент математики, А.Б.Н. Сиал колледж Кух Бекар, У.Б, Пин-736101

Индия

\footnotetext{
Данная статья связана с устойчивым МГД пограничным слоем электропроводной нанодисперсии вдоль вертикальной проницаемой поверхности с переменными условиями потока. Транспортная модель включает в себя эффект броуновского движения с термофорезом в присутствии химической реакции и теплового излучения. Групповой метод использутся для нахождения симметрии ведущих уравнений с частными производными. Редуцированные уравнения решаются численно с исполъзованием метода Рунге-Кутта четвертого порядка и метода съемки прогноза тепло- $и$ массообмена характеристик потока нанодисперсии. Численные результаты представлены в виде графиков и таблии, для нескольких наборов значений привлеченных параметров задачи и детально обсуждены с физической точки зрения.
}

Ключевые слова: нанодисперсия, преобразование группы Ли, магнитное поле, химическая реакиия, броуновское движение, тепловое излучение. 